\title{
Improving patient safety: moving beyond the "hype" of medical errors
}

\author{
Alan J. Forster, Kaveh G. Shojania, Carl van Walraven
}

$\mathrm{T}$ The recent Canadian Adverse Event Study found that $7.5 \%$ of hospitalizations were associated with adverse events and that 1 in 6 patients with an adverse event died. ${ }^{1}$ These findings, which are not unique to Canada, ${ }^{2}$ have resulted in some laudable initiatives, including creation of the Canadian Patient Safety Institute. We are nonetheless concerned that health care administrators, patient safety advocates and even researchers believe that solutions to most safety problems already exist, and that the only problem is educating health care providers to use them. We disagree.

For example, the Institute of Healthcare Improvement, a US-based nonprofit organization, launched the "100K Lives" campaign, in which it recommends several interventions to tackle 6 "safety" problems. ${ }^{3,4}$ Although some of the recommended interventions (e.g., ASA therapy to reduce mortality after myocardial infarction) are supported by high levels of evidence, several are not. For an example of the latter, as a means to minimize preventable deaths the campaign suggests implementing a rapid-response team of clinicians to bring critical expertise quickly to the bedside of patients with dangerously abnormal vital signs. In theory, such an intervention could be effective, and some observational data do support its use; ${ }^{4,5}$ however, the only well-designed clinical trial evaluating rapid-response teams found that the intervention had no effect on important clinical outcomes. ${ }^{6}$ Accepting recommendations not based on evidence may lead to no measurable improvement in clinical outcomes, while resources are wasted and the credibility of all patient safety efforts is reduced.

Even before we institute specific programs to reduce error, we need to reduce gaps in our knowledge, including our limited understanding of how to measure adverse events and their clinical significance. Evaluation of adverse events requires first a robust method for detecting them and second a means to rank their clinical importance. Only then can we be sure that we will be able to reach the third step: programs to reduce the frequency of clinically serious adverse events.

How can the presence of an adverse event be determined? Investigators usually ask trained physicians to assess the clinical information on patients who experience poor outcomes and use implicit criteria to rate whether the outcome resulted from the quality or nature of the medical care or the progress of the underlying illness. The subjective nature of this process leads to disagreement between physician reviewers and to wide variations in the reported prevalence of adverse events. ${ }^{7-9}$

To illustrate this problem, consider data from a recent study ${ }^{10}$ where we determined the proportion of 328 medical patients who experienced an adverse event after hospital dis- charge. The proportion of patients judged to have undergone an adverse event varied not only among the 3 reviewers (23\% v. $27 \%$ v. $21 \%$ ) but also by how their responses were aggregated (unanimous agreement $15 \%$ v. a 2 -out-of-3 majority $23 \%)$. Thus, depending on how adverse events were defined, prevalence varied from $15 \%$ to $27 \%$. In most clinical research, a $12 \%$ absolute change in the major outcome of interest would hold substantial interest. For patient safety, these data show that such variations could simply be related to who reviewed the case and how agreement was achieved. For $4^{1,11-13}$ of 6 major studies, adverse-event rates reflected judgments by 1 reviewer per case, whereas for the other $2,{ }^{14,15}$ only 2 physicians were used. Our data on the variation among reviewers suggest that these previous studies may have inaccurately defined the extent of safety problems.

The second issue is whether or not adverse events are clinically important. Although adverse events are known to lead at times to permanent disability or even death, most cause only temporary symptoms. ${ }^{1,11-15}$ One of the barriers to measuring the clinical impact of adverse events is distinguishing the adverse event from other causes of poor outcomes. Most studies have merely associated the occurrence of adverse events with outcomes, rather than tried to establish the more relevant causal relation. Consider a critically ill patient who develops a pneumothorax as a result of an erroneously inserted subclavian line. If the patient dies, her death is most likely the result of her critical illness rather than the pneumothorax, which is rarely life-threatening. However, if standard patient-safety research methodology were applied to this case, the patient would have had a "preventable adverse event" (the pneumothorax, caused by an error in line insertion) associated with the outcome "death." In other words, there is no assessment of the degree to which the adverse event contributed to the patient's eventual death. This determination has not been adequately addressed in any of the major studies of adverse events. ${ }^{1,11-15}$

To the best of our knowledge, only 1 study $^{9}$ has assessed the effect of adverse events on patients' ultimate outcomes by asking reviewers to estimate the probability that patients would have lived longer had the adverse event not occurred. The reviewers deemed that only $6 \%$ of patients who died would have been expected to live an additional 3 months had the identified care problems not occurred.

Lastly, there are major gaps in knowledge about patientsafety practices. In a systematic review of 80 patient-safety interventions, ${ }^{16}$ those with reasonable supporting evidence consisted largely of clinical therapies such as prophylaxis of 
venous thromboembolism. Frequently espoused "systembased" interventions, such as improving facility design and work flow with technology and robotics, adding forcing functions to procedures (e.g., automatic stop orders for Foley catheters ${ }^{17}$ or precautions against the storage of concentrated potassium solutions with ward stock) ${ }^{18}$ and improving product labels have only modest supporting evidence. For example, computerized practitioner order entry has decreased medication errors in several studies but has not significantly reduced actual adverse drug events. ${ }^{19}$ The benefits of incident reporting, root-cause analyses and promoting a "culture of safety" are even less clear.

Even the evidence supporting apparently established safety practices is in a state of flux. For example, although perioperative $\beta$-blockers received a high evidence rating in the patient safety review, ${ }^{16}$ a recent systematic review ${ }^{20}$ that included data from several trials published subsequently concluded that the evidence was insufficient to support their use; in fact, the dominant clinical outcome found was bradycardia requiring treatment. Thus, the most recent data on this safety intervention suggest that not only does it fail to improve outcomes, it may in fact worsen them.

Without more robust methods to determine when an adverse event has taken place and a better understanding of the clinical importance of adverse events, it will be impossible to set priorities for evaluating intervention strategies to reduce the chances of such events.

Given the magnitude and severity of the problem, can we afford to wait for the high-quality evidence of randomized clinical trials? Or should we just, as some have argued, get on with it: ${ }^{21}$ In situations where an important problem exists and evidence for a solution does not, decision-makers could use an approach analogous to that used by clinicians faced with imperfect evidence. A framework for informing such decisions might include the importance of the targeted problem (its combined prevalence and severity), the strength of the available evidence supporting the intervention, and the potential for adverse collateral effects from the intervention. Reasonable interventions should be piloted in accordance with our understanding of the problem's causes and after careful risk assessment. A thoughtful evaluation of the implementation process should be undertaken and the results published so that others can learn.

Our recommendations may appear overly cautious to some, but we are reminded of the words of Henry Louis Mencken when he stated "For every complex problem, there is a solution that is simple, neat, and wrong." Rushing to implement poorly tested interventions that target problems of unclear significance may do little to help and ultimately may even discredit the endeavour, an effect that all of us would hope to avoid.

\section{This article has been peer reviewed.}

From the Department of Medicine and the Ottawa Health Research Institute, University of Ottawa (Forster, Shojania, van Walraven) and the Institute for Clinical Evaluative Sciences (van Walraven), Ottawa, Ont.
Competing interests: None declared.

Contributors: All authors were involved in the drafting and critical revision of the manuscript. They all gave final approval of the version to be published.

Acknowledgements: Alan Forster and Carl van Walraven are Ontario Ministry of Health Career Scientists. Alan Forster holds the 2004 PSI Foundation Scholarship in Innovative Health Services Research. Kaveh Shojania holds a Canada Research Chair in Patient Safety and Quality Improvement.

\section{References}

1. Baker GR, Norton PG, Flintoft V, Blais R, Brown A, Cox J, et al. The Canadian Adverse Events Study: the incidence of adverse events among hospital patients in Canada. CMA7 2004;170(11):1678-86.

2. Corrigan J, Kohn LT, Donaldson MS, editors. To err is buman: building a safer bealth system. Washington: National Academy Press; 2000.

3. Institute for Healthcare Improvement. $100 \mathrm{~K}$ Lives Campaign. Available: www.ihi.org/IHI/Programs/Campaign/Campaign.htm?TabId=2 (accessed 2005 Aug 12).

4. Buist MD, Moore GE, Bernard SA, Waxman BP, Anderson JN, Nguyen TV. Effects of a medical emergency team on reduction of incidence of and mortality from unexpected cardiac arrests in hospital: preliminary study. BM7 2002 324(7334):387-90.

5. Bellomo R, Goldsmith D, Uchino S, Buckmaster J, Hart GK, Opdam H, et al A prospective before-and-after trial of a medical emergency team [comment] Med 7 Aust 2003;179(6):283-7.

6. Hillman K, Chen J, Cretikos M, Bellomo R, Brown D, Doig G, et al. Introduction of the medical emergency team (MET) system: a cluster-randomised controlled trial. Lancet 2005;365(9477):2091-7.

7. Thomas EJ, Studdert DM, Runciman WB, Webb RK, Sexton EJ, Wilson RM, et al. A comparison of iatrogenic injury studies in Australia and the USA. I: Context, methods, casemix, population, patient and hospital characteristics. Int 7 Qual Health Care 2000;12:371-8.

8. Thomas EJ, Lipsitz SR, Studdert DM, Brennan TA. The reliability of medical record review for estimating adverse event rates [published erratum appears in Ann Intern Med 2002;137:147]. Ann Intern Med 2002;136:812-6.

9. Hayward RA, Hofer TP. Estimating hospital deaths due to medical errors: preventability is in the eye of the reviewer. FAMA 2001;286:415-20.

10. Forster AJ, Clark HD, Menard A, Dupuis N, Chernish R, Chandok N, et al. Adverse events affecting medical patients following discharge from hospital CMA7 2004;170(3):345-9.

11. Thomas EJ, Studdert DM, Burstin HR, Orav EJ, Zeena T, Williams EJ, et al Incidence and types of adverse events and negligent care in Utah and Colorado. Med Care 2000;38:261-71.

12. Vincent C, Neale G, Woloshynowych M. Adverse events in British hospitals: preliminary retrospective record review. BMF 2001;322:517-9.

13. Davis P, Lay-Yee R, Briant R, Ali W, Scott A, Schug S. Adverse events in New Zealand public hospitals I: occurrence and impact. NZ Med 7 2002;115:U271.

14. Wilson RM, Runciman WB, Gibberd RW, Harrison BT, Newby L, Hamilton JD. The Quality in Australian Health Care Study. Med 7 Aust 1995;163:458-71.

15. Brennan TA, Leape LL, Laird NM, Hebert L, Localio AR, Lawthers AG, et al. Incidence of adverse events and negligence in hospitalized patients: results of the Harvard Medical Practice Study I. N Engl f Med 1991;324:370-6.

16. Shojania KG, Duncan BW, McDonald KM, Wachter RM, Markowitz AJ. Making health care safer: a critical analysis of patient safety practices [review]. Evid Rep Technol Assess (Summ) 2001;(43):i-x, 1-668.

17. Cornia PB, Amory JK, Fraser S, Saint S, Lipsky BA. Computer-based order entry decreases duration of indwelling urinary catheterization in hospitalized patients. Am 7 Med 2003;114(5):404-7.

18. Kaushal R, Shojania KG, Bates DW. Effects of computerized physician order entry and clinical decision support systems on medication safety: a systematic review. Arch Intern Med 2003;163(12):1409-16.

19. Tubman M, Majumdar SR, Lee D, Friesen C, Klassen TP. Best practices for safe handling of products containing concentrated potassium. BMF 2005;331 (7511):274-7.

20. Devereaux PJ, Beattie WS, Choi PTL, Badner NH, Guyatt GH, Villar JC, et al. How strong is the evidence for the use of perioperative в blockers in noncardiac surgery? Systematic review and meta-analysis of randomised controlled trials [review]. BM7 2005;331(7512):313-21.

21. Leape LL, Berwick DM, Bates DW. What practices will most improve safety? Evidence-based medicine meets patient safety. FAMA 2002;288:501-7.

Correspondence to: Dr. Alan J. Forster, 1053 Carling Ave., Rm. C406, Ottawa ON K1Y 4E9; fax631761-5492; aforster@ohri.ca 